\title{
IDENTITAT, IDEOLOGIA I ARGUMENTACIÓ EN LES CARTES AL DIRECTOR DEL DIARI LEVANTE EMV
}

\section{IDENTITY, IDEOLOGY AND ARGUMENTATION IN THE LETTERS TO THE EDITOR OF LEVANTE EMV JOURNAL}

\author{
ENRIC Portalés LloP \\ Universitat Jaume I* \\ eportale@uji.es
}

Recibido: 03/07/2017

Aceptado: 19/09/2017

\section{Resum}

El nostre estudi es basa en l'anàlisi de l'autopresentació dels escriptors de cartes al director del diari Levante EMV. N'hem seleccionat $127 \mathrm{i}$ hem dividit el treball en la identificació dels autors per la informació que ells mateixos aporten (nom, sexe) i aquella que es pot inferir de les tries pragmaestilístiques que han fet. Concloem que els indicis textuals triats (persones gramaticals, possessius, etc.) transmeten tot d'informacions rellevants sobre la identitat dels autors, la defensa d'un determinat món ètic, una ideologia, etc. Si l'autor ha controlat minuciosament l'aparició d'aquells indicis, reforçarà l'argumentació del seu escrit; si no ho ha fet, pot contribuir a una interpretació contrària dels seus arguments.

PARAULES CLAU: Ethos, autopresentació, argumentació, identitat, anàlisi del discurs.

\begin{abstract}
Our study aims at analysing how writers introduce themselves in texts written to the Letters to the Editor section of Levante EMV. We have compiled 127 letters, paying attention to how these writers identify themselves throughout the information and data they provide (name, gender) and, additionally, how this information can be inferred by the pragmatic/stylistic strategies selected. We understand that textual implications (grammar and lexical choices) offer relevant information about the authors' identity, the defence of a given ethical world, a specific ideology, etc. If authors can control the use of those specific choices, the argumentation of their writing will be reinforced; if this is not fulfilled, it may contribute to a wrong interpretation of their own arguments.

KEYWORDS: Ethos, self-introduction, argument, identity, discourse analysis.
\end{abstract} * El present treball s'inscriu en el Projecte P1-1B2015-62, Funcions educatives de la literatura a l'entorn de les
emocions, la imaginació i la construcció d'identitats, de la Universitat Jaume I.

Para citar este artículo / To cite this article: Portalés Llop, Enric (2017). Identitat, ideologia i argumentació en les cartes al director del diari Levante EMV. ELUA, 31: 251-268. doi: 10.14198/ ELUA2017.31.13

Enlace / Link: http://dx.doi.org/10.14198/ELUA2017.31.13 


\section{INTRODUCCIÓ}

Les cartes al director dels mitjans de comunicació escrits s'han considerat al llarg del temps com un gènere híbrid entre el periodisme d'opinió (Gomis, 1991; 2008) i una mena de fòrum públic de participació ciutadana en la gestió de la informació (Van Dijk, 2009). Fins a la generalització de les xarxes de comunicació social (sobretot, Twitter i Facebook) i l'aparició de les versions digitals dels periòdics que permeten comentaris dels lectors, aquesta era l'única possibilitat d'intervenció dels ciutadans anònims en els diaris o revistes, llevat d'alguns casos (no gaires) en què es podia establir relació telefònica amb alguns mitjans escrits a través dels contestadors automàtics ${ }^{1}$.

En una investigació prèvia (Portalés, 2016) que tenia com a objectiu l'anàlisi pragmaestilística del gènere en dos diaris que publicaven cartes al director en català (Ara i La Vanguardia) vàrem constatar que els escriptors empraven l'autopresentació per donar veracitat al contingut dels seus escrits i això contribuïa també a la identificació de l'autor amb uns determinats valors ètics. Hem volgut endinsar-nos ara en l'anàlisi d'aquesta autopresentació en un diari publicat a València i comprovar quines regularitats es manifesten a l'hora d'identificar els autors amb els col·lectius (socials, polítics, religiosos, etc.) amb què s'associen. La tria del periòdic Levante EMV per al nostre estudi es basa en dues raons: en primer lloc, perquè és, sense dubte, el de major difusió entre els que es publiquen al País Valencià (segons els darrers resultats de l'EGM entre octubre de 2016 i maig de $2017^{2}$ ) i, en segon, perquè el diari permet la publicació de cartes tant en castellà com en català.

Centrem l'anàlisi, doncs, en 127 cartes al director publicades en la versió digital del Levante durant el període que va de l'1 de gener de 2016 al 28 de febrer de 2017 per raons de delimitació del corpus i perquè considerem que el període és significatiu (dos mesos) i el nombre d'escrits abundós. El fet que l'elecció de les cartes tingui en compte només el període en què es publiquen condiciona, al nostre parer, que els resultats siguin més significatius que si s'haguessin elegit prèviament uns textos que responguessin a unes característiques (estilístiques o de contingut) predeterminades.

Del conjunt de les cartes estudiades (127), 110 foren publicades en castellà i 17 en català. Per a l'anàlisi de les cartes hem emprat un motor de recerca automàtic de corpus que permet la selecció dels mots i la seva contextualització.

L'estructura d'aquest estudi respon a una explicació succinta de la base teòrica en què ens movem, sobretot per a la introducció del concepte d'ethos per a, posteriorment, endinsar-nos en l'anàlisi de les autopresentacions prèvies dels autors (ethos prediscursiu) i de les pròpies identificacions dels escriptors a dins del text (ethos discursiu), tant si aquella identificació es produeix de manera explícita (ethos dit) o implícita (ethos mostrat); en aquest darrer cas, considerem important la diferenciació entre les cartes escrites en català i les que ho són en espanyol, perquè el nostre estudi es basa en marques pragmaestilístiques que identifiquen l'autor amb un determinat territori, ideologia, etc., per a la qual cosa havíem d'esbrinar si la llengua és també un factor d'identificació. Finalment, ens fixem en la manera d'adscriure's a un determinat col·lectiu per reclamar-ne el suport argumentatiu mitjançant l'ús de pronoms o persones gramaticals.

1 És ben coneguda, en aquest sentit, la influència de la secció "El cabinista" de Las Provincias durant el període de la transició i fins el 1999 en què Maria Consuelo Reyna deixà la direcció del diari.

2 http://www.aimc.es/-Datos-EGM-Resumen-General-.html 


\section{FONAMENTS TEÒRICS}

En les cartes al director els emissors parlen generalment en el seu propi nom, per això la persona gramatical més característica és la primera del singular. Ara bé, els autors alternen (amb diverses finalitats que tractarem d'esbrinar) l'ús de la primera del plural o la tercera, ja siguin del singular o del plural. Per a la caracterització de la presentació (o autopresentació) de l'emissor en el gènere tenim en compte els treballs de l'anàlisi polifònica (Ducrot, 1972), la represa del concepte aristotèlic d'ethos a partir de la nova retòrica (Perelman i OlbrechtsTyteca, 1989) i la seva adaptació a l'anàlisi del discurs, tant per part de Maingueneau (1987 i 2010) com d'Amossy (1999 i 2010).

La retòrica ha mantingut al llarg de la història la diferenciació entre ethos, pathos i logos, més o menys com Aristòtil la va plantejar inicialment fins que apareix l'anomenada nova retòrica que estableix la solidaritat entre l'orador i el discurs que emet, el qual, de fet, es construeix també atenent a la personalitat de l'auditori:

A causa de la interacción constante entre el juicio que se emite sobre el orador y el que alude al discurso, quien argumenta expone continuamente un poco su prestigio, el cual aumenta o disminuye según los efectos de la argumentación. Una argumentación vergonzosa, floja o incoherente, lo único que hace es perjudicar al orador. (Perelmann i Olbrechts-Tyteca, 1989: 491)

Serà a partir de la consideració que la imatge de l'orador es construeix amb la col·laboració entre el discurs, la persona (l'orador) i l'auditori que confluiran en l'estudi d'aquesta imatge (de l'ethos, de fet) tot de diverses disciplines (psicologia, pragmalingüística, anàlisi del discurs, sociologia, etc.). La teoria de Perelman i Olbrechts-Tyteca, tanmateix, sembla relacionar-se millor amb l'anàlisi del discurs que s'inscriu en el marc de la interacció comunicativa.

Ducrot (1972) integra la noció clàssica de l'ethos en la seva teoria polifònica i l'atribueix al subjecte parlant (locutor L), el qual separa de l'ésser en el món (locutor $\Lambda$ ), més o menys, el subjecte que parla i el subjecte que mostra, respectivament.

De manera distinta, Maingueneau (2010) diu que el concepte s'aplica, fonamentalment, en l'acte d'enunciació i el defineix com l'encarnació de l'enunciador que fa la funció de garant, el qual relaciona no sols amb un cos i un caràcter, sinó també en el reconeixement que l'alocutari atorgarà a un determinat món ètic. Tanmateix, reconeix que sovint, el públic construeix representacions de l'enunciador abans que el locutor parli, i doncs, distingeix entre l'ethos prediscursiu i el discursiu. Per a Amossy (1999) aquest ethos prediscursiu es formaria per l'autoritat institucional del locutor, per la seva legitimitat. En canvi, l'ethos discursiu serà aquell que se'ns presenta quan el destinatari llig un text d'un autor desconegut i se n'ha de construir una imatge a través únicament de l'enunciat. Aquest, seguint la divisió de Ducrot de què ja havíem parlat, s'hauria de diferenciar entre ethos dit i ethos mostrat, que nosaltres relacionem amb l'autopresentació.

El locutor pot presentar-se amb un ethos dit (sóc metge, sóc mestre, sóc funcionària...) que mobilitza immediatament tota una sèrie de representacions col-lectives estereotipades en el destinatari o mostrar-se únicament a través del discurs, la qual cosa obligarà l'alocutari a construir l'ethos a partir d'indicis textuals.

El gènere que ens ocupa ofereix veu als qui no en tenen, entès des de la perspectiva que, en general, els mitjans de comunicació són escrits amb la intenció de mantenir un cert 
estat de les coses que afavoreixi els grups dominants de la societat (Van Dijk, 1993). Ara bé, si l'escriptor de les cartes vol tenir repercussió i que les seves tesis siguin compartides, acceptades, defensades pels lectors del periòdic al qual les envia, cal que formi en els interlocutors una imatge de si mateix que provoqui credibilitat i confiança, també és convenient que aquesta imatge transmeti coneixement, domini d'allò que es parla. La imatge es manifesta de diverses maneres a través de l'enunciat ja que, només en algunes ocasions, podem parlar d'ethos prediscursiu (ethos previ, en la terminologia d'Amossy, 2010) el qual, segons Maingueneau (2010) no es manifesta en textos d'autors desconeguts, com ocorre en la majoria dels casos que ens ocupen.

No voldríem donar a entendre que els autors de les cartes al director són completament desconeguts pels lectors del mitjà en el qual surten publicades perquè les cartes anònimes $\mathrm{o}$ firmades amb pseudònims pertanyen als inicis de la premsa escrita (s. XVIII) segons WahlJorgensen (2007); pel contrari, en l'actualitat, cap periòdic permet la publicació d'una carta que no n'identifiqui el nom, l'adreça i el DNI de l'autor (tot i que el mitjà només en publica el nom i la ciutat per raons de protecció dels escriptors); encara que un nom i una població no ens aporten suficient informació per fer-nos una idea d'aquesta imatge prediscursiva de què parlem. Només la podem identificar en aquells casos en què l'autor es manifesta com una veu que representa algú, és a dir, que s'erigeix en veu autoritzada d'un col·lectiu o d'una institució.

\section{ETHOS PREDISCURSIU}

La primera identificació amb què ens trobem és el nom de l'escriptor o escriptora. En general aquesta dada només ens aportarà informació si qui signa és un personatge conegut de l'esfera pública (en aquest cas, valenciana) i si es tracta d'un home o una dona. En ambdós casos, la predisposició del lector es veu afectada a la interpretació de l'escrit. Molt menys, certament, en el cas del nom si no és conegut; però de manera significativa en el cas del sexe.

En els nostres treballs anteriors ${ }^{3}$, hem pogut observar que no hi havia una diferència significativa en l'autoria de les cartes pel que fa al sexe (hem analitzat els periòdics La Vanguardia i Ara i en ambdós, trobem un equilibri quasi exacte en les cartes escrites per homes i dones) i això, malgrat que la majoria d'estudis anteriors confirmaven que la presència de la dona era molt menor (Wahl-Jorgensen, 2007).

És interessant puntualitzar que Habermas (1989) exclou les dones i els gais dels llocs d'expressió de l'esfera pública burgesa així com Fraser (1990) que considera aquests grups com a esfera subalterna, contrapública, que es manifesta en mitjans d'expressió paral·lels a l'esfera burgesa:

This history records that members of subordinated social groups -women, workers, peoples of color, and gays and lesbians- have repeatedly found it advantageous to constitute alternative publics. I pro-pose to call these subaltern counterpublics in order to signal that they are parallel discursive arenas where members of subordinated social groups invent and circulate counterdiscourses, which in turn permit them to formulate oppositional interpretations of their identities, interests, and needs. (Fraser, 1990: 67)

3 Portalés, 2017. 
Pel contrari, en el cas que ens ocupa hem trobat un percentatge molt reduït de cartes escrites per dones (només un 15\%) que coincideix amb els resultats d'un estudi sobre les cartes aparegudes en la premsa danesa (Nielsen, 2010). Ara bé, hem de destacar que no hi ha diferència temàtica en les cartes per raó de sexe.

Un altre dels identificadors de les cartes és la procedència de l'escriptor. En el cas dels periòdics editats a les grans ciutats, la major part de les col·laboracions pertanyen al nucli urbà, en aquest cas València, d'on n'arriben el 71\% (90 cartes en total). També és el lloc on més lectors s'hi dediquen, és a dir, on més escriptors repeteixen cartes. De fet, n'hi ha un que n'escriu vuit en un període de dos mesos.

El fet que els escriptors siguin majoritàriament residents a València determina en gran mesura els temes que es tracten en la secció, ja que, sovint, una carta rep una resposta i l'assumpte esdevé una mena d'hipertema. En el nostre cas, un dels més recurrent és el del carril bici ( 9 ocurrències): l'ús que se'n fa, les molèsties de les obres de condicionament, etc.

Pel que fa als textos amb una identificació explícita dels autors amb la seva activitat professional, grup o associació a la qual pertanyen en l'entorn paratextual, només n'hem trobat 7 exemples.

El primer cas [1], és un escriptor d'Alfafar que es presenta amb el seu número de soci del València CF per a contar un malson en el qual el nou president abandonava el club després de vendre tots els actius sense fer front als deutes ni a les obligacions a què s'havia compromès. És evident que aquesta identificació pretén agreujar les pors dels aficionats valencians perquè les manifesta un soci amb una numeració molt baixa. Entenem que el compromís amb una institució (com un club de futbol) es pot mesurar pel temps que hom hi ha estat relacionat.

En el segon [2], parla el President del Gremi de Mestres del Ventall de València per agrair que un article aparegut en el diari es referís al ventall valencià i hi donés la importància que mereix. Enlloc no diu que parli en nom del gremi, ni que en sigui la veu autoritzada, però el fet d'identificar-se com a tal, provoca en el lector una interpretació complaent de tot el col·lectiu.

El tercer cas [3], mostra la versió que signen dues professores del col·legi Maria Immaculada de Carcaixent sobre una notícia apareguda en el Levante ${ }^{4}$. El diari havia llençat que un grup d'estudiants i monitors que s'hostatjaven en un alberg no havien volgut abandonar-lo després que els equips de rescat els haguessin anat a buscar. La narració de les professores contradiu (en part) la notícia del periòdic i per això, dos testimonis autoritzats (dues professores que hi eren) donen una versió més creïble que no pas la del diari.

El quart exemple que reportem [4], és el d'una dona que reclama la normalització lingüística de l'església arran d'una visita al Museu de la catedral de València on ha trobat els rètols explicatius escrits únicament en castellà. L'autora s'identifica com pertanyent a la Plataforma pel Dret a Decidir, col·lectiu que reclama la participació ciutadana en les institucions i la vida política valencianes des del 2013. El fet d'autopresentar-se sota aquesta etiqueta hauria de tenir una repercussió positiva perquè demostra que l'escriptora està compromesa amb els signes d'identitat valencians, com ara la llengua; en canvi al País Valencià pertànyer a aquesta plataforma es pot associar a contravalors com ara l'independentisme o la radicalització i, justament, pot produir, segons en quins lectors (i en el Levante se n'hi mostren bastants) l'efecte contrari.

4 http://www.levante-emv.com/comunitat-valenciana/2017/01/21/piden-rescate-despues-decidenquedarse/1518225.html. Consulta 6 de març de 2017. 
Un nou cas [5] de presentació prèvia al text és el d'una nena que estudia $2 \mathrm{n}$ d'ESO a l'IES Barri del Carme de València (12 o 13 anys). L'autora recorda la celebració del Dia Internacional de la Pobresa (17 d'octubre) i reclama que les famílies amb massa diners collaborin perquè tothom pugui dormir sota un sostre. Resulta emotiu que una nena s'amoïni i faci pública aquesta preocupació per les persones menys afavorides, perquè pot produir el mateix efecte que la publicitat quan empra aquest recurs amb una finalitat similar (Gómez i Blanco, 2005).

La carta següent [6] també qüestiona una informació apareguda al diari (ara, però d'un article d'opinió) i critica les dades en què es basa. El Comitè d'Empresa de l'Agència Valenciana de Turisme havia fet públic un comunicat de recolzament a tres funcionaris condemnats pel Tribunal Superior de Justícia de la Comunitat Valenciana arran de la trama Fitur del cas Gürtel, comunicat que l'autor de l'article (Sergi Pitarch) atribueix a un grup de 14 delegats sindicals que ho serien des de l'any 2005. Els autors de la carta que s'identifiquen com dos ex-membres d'aquell comitè, neguen aquestes circumstàncies. Naturalment, el fet d'autopresentarse com a membres (o ex-membres) d'aquell col·lectiu, dóna credibilitat a la informació, exactament com passava en el cas de les dues professores que hem analitzat més amunt.

El darrer dels casos [7] és el d'un metge (probablement una de les identitats més valorada socialment en la nostra cultura) que a més es presenta com a president de la Societat Valenciana de Medicina Familiar i Comunitària (SVMFIC). L'autor fa una defensa de la mort digna i l'allunya d'una suposada acceleració del traspàs o d'un manteniment artificial de la vida. Reivindica, de fet, la tasca dels professionals sanitaris d'atenció primària en l'acompanyament del pacient perquè mantingui la dignitat i mori sense dolor. I tot això com a resposta d'un altre article d'opinió en què es relacionava l'activitat dels sanitaris amb la prolongació de la vida o l'acceleració de la mort ${ }^{5}$. La versió d'un metge que es dedica (com manifesta) a aquesta activitat pal·liativa dóna molta més credibilitat, lògicament, que la d'una articulista.

El concepte d'ethos prediscursiu es relaciona amb el de façana en el sentit que li atorga Goffman (1981) perquè aquesta autopresentació com a membres de col·lectius condiciona la percepció de credibilitat que el lector tindrà en llegir-los: "La fachada se convierte en una 'representación colectiva' y en una realidad empírica por derecho propio." (1981:39)

Volem detenir-nos en un factor important en la nostra investigació que no es tracta en la majoria dels estudis consultats (si no són comparatius de diversos diaris: Rojas Lizana, 2009 o Young, 2013): la tria de la llengua. Levante és un diari que es publica en castellà', però té seccions escrites en català (Postdata, per exemple) i permet que les cartes i altres articles d'opinió també s'hi escriguin, de fet, en les normes d'edició de les cartes al director no hi ha cap referència al respecte.

La tria de la llengua no hauria de ser, en principi, cap senyal d'autopresentació, ara bé, al País Valencià, la llengua representa una identitat relacionada no sols amb un territori, sinó també (com veurem tot seguit) amb una determinada ideologia. L'escriptura en català s'adscriu en les nostres cartes a posicions sociolingüísticament compromeses, mentre que l'escriptura en castellà no manifesta, en principi, cap tendència que es justifiqui per l'ús de la llengua. ${ }^{7}$

5 http://www.levante-emv.com/opinion/2017/02/15/dignidad-personas-final-vida/1528975.html. Consulta 6 de març de 2017.

6 Des de 1'1 de maig de 2016 també compta amb una edició digital en català.

7 Per a una anàlisi de la situació sociolingüística valenciana, Pradilla, 2008 i més recentment, Conill, 2016. 


\section{ETHOS DISCURSIU}

Entenem per discursiva, aquella façana que l'autor conscientment expressa en el seu text identificant-se amb col·lectius ("soy valenciano", "soy productor de mandarinas"); mentre que associem l'ethos mostrat amb allò que el lector pot inferir en el mateix text de les expressions que l'autor ha anat deixant com una mena d'esquer ("Cada año, en diciembre recibía una carta con la revalorización de las pensiones.", "Pero la Iglesia y los católicos no tenemos miedo").

Ambdues presentacions tenen conseqüències imprevistes quan els escriptors no són professionals. Si l'autor no és minuciós en la tria dels mots i les estructures, pot presentar-se com el contrari del que pretenia. Cosa que Goffman reconeix en l'apartat corresponent al manteniment del control expressiu:

La coherencia expresiva requerida para toda actuación señala una discrepancia fundamental entre nuestros sí mismos demasiado humanos y nuestros sí mismos socializados. Como seres humanos somos, presumiblemente, criaturas de impulsos variables, con humores y energías que cambian de un momento a otro. En cuanto caracteres para ser presentados ante un público, sin embargo, no debemos estar sometidos a altibajos. (Goffman, 1981:67)

En el mateix sentit es manifesta Maingueneau en un treball que analitza la divergència entre l'ethos dit i el mostrat en el web de contactes Meeting a França (2010: 218). De vegades els participants en aquell web, es presenten com a persones humils, senzilles i el seu discurs mostra ciutadans cultes, lletraferits; el mateix es dóna a l'inrevés, naturalment. Només com a mostra podem proposar l'exemple de la carta ja comentada abans [3] de les dues professores. En un fragment afirmen:

A lo que sí nos negamos fue a que el autobús accediese hasta las inmediaciones del campus Moragete, ya que el acceso en dichas condiciones era imposible y muy peligroso para un vehículo de tales dimensiones.

La conjunció dels qualificatius imposible i muy peligroso podria reduir la credibilitat d'unes professores simplement per no haver controlat de manera minuciosa el discurs: únicament si l'accés fos possible, seria muy peligroso. I és que, sovint, l'atac a la credibilitat d'un discurs no es fonamenta en la certesa de la informació rellevant, sinó en qüestions aparentment secundàries o irrellevants que posen en dubte la validesa del text; una mena de fal·làcia discursiva (ignoratio elenchi) bastant eficaç en la disputa dialèctica. Ho podem comprovar en un parell d'exemples.

El primer, extret de la mateixa carta. Les professores qüestionen la notícia apareguda en el diari atenent inicialment a dades numèriques que, en principi, no consideraríem fonamentals pel que fa a la versió dels fets que pretenen aclarir: "En primer lugar, el número exacto de menores era de 53 y 16 las personas adultas (entre monitores, profesorado y responsables del complejo educativo)." Pel contrari, la notícia deia: "donde habían quedado atrapados en un albergue alrededor de 40 niños y profesores."

El segon, d'una altra carta a què ja havíem fet referència també [6]; la d'uns exmembres del comitè d'empresa de l'AVT i encara una altra d'un company dels treballadors 
de l'agència condemnats en la trama Fitur del cas Gürtel. Ambdues retreuen a l'autor de l'article d'opinió que origina la protesta (Sergi Pitarch) les errades que apareixen en el seu article, errades també (com en el cas anterior) contextuals. La primera, se centra en el nombre de delegats sindicals del comitè d'empresa que signaren una carta de suport als treballadors condemnats (14 segons Pitarch; 13 segons els autors de la carta) i en l'afirmació que els delegats eren els mateixos que en 2005, perquè des d'aleshores no s'hi havien fet eleccions sindicals; cosa que els autors contradiuen argüint que el 2015 es renovà totalment el comitè. La carta del company [8] insisteix en aquesta darrera errada del columnista: "el comité fue elegido el año pasado, no hace 12 años como indica."

Com veiem, ni el nombre d'estudiants i professors que protagonitzaren els fets a Moraguete (Casas del Río, Requena) ni el nombre de membres del comitè d'empresa o els anys que es mantinguessin en el càrrec són fonamentals en l'argumentació d'una versió dels fets diferent, ni en la inconveniència d'un article d'opinió que critica la defensa de treballadors condemnats en un cas de corrupció política. Ara bé, és cert que la informació periodística ha de contrastar-se amb la realitat i qualsevol errada que es pugui descobrir hi treu credibilitat.

\subsection{Ethos dit}

Ens endinsarem ara en l'anàlisi de l'autopresentació de l'ethos discursiu dels redactors de cartes al director. Veurem com els locutors s'investeixen de credibilitat, honestedat, testimoniatge o qualsevol dels valors que col·lectivament considerem favorables perquè s'arribi a l'empatia amb l'escrit d'un desconegut. En paraules de Goffman (1981:47): “Cuando el individuo se presenta ante otros, su actuación tenderá a incorporar y ejemplificar los valores oficialmente acreditados de la sociedad, tanto más, en realidad, de lo que lo hace su conducta general."

El locutor es presenta com a mestra, periodista, jove, estudiant..., cosa que contribueix, en part, a la creació de clixés o estereotips en el lector (Amossy i Herschberg, 1997), i per tant, condiciona aquesta percepció a través del que diu en l'enunciat. Per altra banda, existeix la possibilitat que el lector es faci una idea de la naturalesa del locutor a través del seu missatge, una percepció autònoma de l'alocutari que, potser, no és controlada per l'autor.

Hi ha algunes cartes en què se'ns mostra clarament la imatge del locutor (ens hi dedicarem tot seguit) i unes altres en què aquesta imatge la deduïm del seu discurs. El locutor de les cartes al director s'ha de construir una màscara ${ }^{8}$ de credibilitat i ho pot fer de dues maneres: molts opten per l'autopresentació com a membres respectables de la comunitat o com a testimonis; i d'altres es manifesten (potser sense pretensions o voluntat manifesta) a través d'inferències que l'interlocutor ha d'interpretar. En el segon cas, doncs, estaríem davant d'una interpretació lliure, no vinculada a la voluntat de l'autor, si més no, de manera generalitzada.

Passem, en primer lloc a analitzar aquells textos en què l'autor ha volgut revestirse d'autoritat mitjançant una presentació explícita. En general, la veracitat, l'autenticitat, l'ethos de credibilitat pot manifestar-se a través de la presentació de l'autor com a testimoni o com a autoritat per emetre una queixa o denúncia. De fet, la majoria d'escriptors que

8 Es tracta simplement d'investir-se d'allò que hom és, malgrat que la professió o la formació siguin només parcialment descriptives. 
critiquen fets injustos o pràctiques errònies, proposen canvis per millorar-los segons el seu parer i per això s'han de revestir d'una imatge creïble, autoritzada (un pare que es queixa dels tràmits per aconseguir el carnet de família nombrosa [9]: "soy padre de familia numerosa", per exemple).

\subsubsection{Identitat, territori i (també) ideologia}

Darrerament, Maingueneau (2014) ha relacionat les diverses dimensions de l'ethos (categòrica, ideològica i experimental) amb unes determinades maneres de parlar. Segurament, els individus associem algunes professions (mestre, metgessa, etc.), identificacions ètniques (francès, alemany, valencià...), ideològiques o experimentals amb un model de llengua que ens conduirà a una recepció més o menys acceptable del discurs: "Ces multiples catégories intéressent la problématique de l'ethos parce qu'elles sont associées stéréotypiquement à des manières de parler" (Maingueneau, 2014:3). Ara bé, ja hem dit més amunt que aquesta relació pot provocar alguns paranys pragmàtics si l'autor del text no controla minuciosament el seu estil.

Analitzarem tot seguit l'ethos categòric, en el qual Maingueneau inclou la identificació ètnica. L'autopresentació dels autors com a pertanyents a un grup identitari que donarà suport a les exigències, crítiques o demandes que motiven les cartes.

Només en les cartes escrites en castellà, apareix expressament indicada la identificació territorial. En quatre casos s'expressa aquesta identitat ("como valenciano" o "soy valenciano") i en tots, aquesta identificació es defineix, curiosament, en contra de l'ús de la llengua que hauria de ser, precisament, el fet identitari diferencial (Ninyoles, 1971).

En el primer exemple [10], l'autor denuncia les subvencions de l'Ajuntament de València a Acció Cultural del País Valencià, que justifica per l'origen català de l'alcalde Joan Ribó: "A nuestro alcalde se le nota que ha nacido en Manresa". A continuació, fa una afirmació contundent: "Valencia será Española (sic) hoy y siempre"; per acabar amb una amenaça: "Tomamos nota para las siguientes elecciones".

En el segon [11], l'autor també denuncia la intenció de la nova Televisió Valenciana d'emetre totes les pel·lícules estrangeres en valencià, cosa que considera excloent per a "los miles de valencianos de La Serranía que solo hablan castellano". Demana que s'actuï com fa ell: "Yo soy valenciano y con mi familia suelo hablar valenciano, pero cuando hay personas que no son valencianas, procuro por educación hacerlo en castellano" ja que (i aquesta és una nova afirmació contundent): "Estoy en España y quiero que me conprendan”. La seva argumentació acaba amb la interrogació retòrica que alerta sobre la catalanitat com un valor negatiu: “¿Estamos haciéndonos catalanes y pediremos la independencia?”

El tercer exemple [12] insisteix en el monolingüisme de la nova televisió amb el mateix argument (la quantitat de persones que no parlen valencià), ara, però, hi ha una sentida defensa de la seva valencianitat, malgrat que no en parli la llengua: "Soy valenciano, nacido en 1953 y enamorado de su terreta, de Castellón a Alicante" i que hagi viscut a l'estranger (per la necessitat que va tenir la seva família d'emigrar): "He regresado a mi tierra 50 años después sin hablar valenciano, aunque lo soy mucho más que algunos que dicen serlo".

En el darrer [13], una autora reclama els seus drets per no haver d'escolaritzar els seus fills en valencià. La seva argumentació es basa en la manca de perspectiva de futur que troba 
en els polítics per afavorir l'ensenyament de "lenguas regionales" i reduir l'ensenyament de l'anglès que "es bastante más importante". L'autora d'aquesta carta es defensa amb la identificació territorial i lingüística que reproduïm sencera:

Soy valenciana, española y europea; en ese orden. Hablo español, valenciano, inglés, francés y tengo unas pequeñas nociones de alemán. En mi casa se les habla a mis hijos en inglés y en francés para que el día de mañana tengan competencias para el mundo que se les viene encima.

Els quatre casos són exemples fefaents de la identitat nacional valenciana entesa en primer lloc com a espanyola i, sobretot, com a divergent de la catalana. No voldríem entrar ara a fer un repàs del fet nacional valencià, però seria convenient referir-nos a les consideracions de R. Castelló pel que fa a la construcció de la identitat (o les identitats) nacional valenciana. Els valencians s'identifiquen amb una nacionalitat espanyola (de fet, és la comunitat amb una llengua pròpia més marcadament espanyolista, Castelló, 2000: 57), amb una de valenciana diferent de la catalana $\mathrm{i}$ amb una altra coincident amb la catalana pel que fa a la llengua, la història i la cultura.

Les tres tendències s'han nodrit al llarg dels anys d'uns mitjans de comunicació afins (Xambó, 2010) i d'una estructura social ben diferenciada. L'espanyola comença a construirse, probablement, a partir dels decrets de Nova Planta (1701-1719) i s'ha anat adobant des de Madrid de manera continuada amb la introducció de funcionaris i la connivència d'institucions pròpies (diputacions, ajuntaments...) per reforçar la fractura territorial entre províncies i impedir-ne la cohesió unitària. La segona i la tercera podrien tenir el mateix inici amb la publicació de Nosaltres els valencians (1962) i El País Valenciano (1962) de Joan Fuster. Ambdues obres (com és sabut) indaguen en l'origen dels valencians i el relacionen, sens dubte, amb la nació catalana; cosa que farà sorgir la identificació amb els Països Catalans i, per contra, una tercera via, d'autoafirmació valenciana independent. Val a dir que de les tres, aquesta darrera sembla la més exigua, ja que majoritàriament la identificació nacional valenciana va lligada a l'espanyola, perquè (com explica Flor, 2010) aquesta tendència que no supera la barrera del regionalisme, no sols és compatible amb la nacionalitat espanyola, sinó complementària: "Soy valenciana, española y europea; en ese orden." diu la mare [13] que es nega a escolaritzar els seus fills en escoles que no tinguin com a llengua vehicular l'espanyol.

\subsection{Ethos mostrat}

\subsubsection{Cartes en valencià}

Entenem per mostrat o mostrada aquella identificació amb el locutor que no és expressada per ell mateix de forma conscient o reivindicativa. Com ja hem dit, és aquella que podem anar rastrejant a través d'indicis que l'autor va deixant al llarg del seu discurs. Ens fixem, sobretot, en els díctics personals (pronoms, possessius, demostratius, persones gramaticals en els verbs...) que relacionen el locutor amb un territori o una defensa de valors determinats: "nuestra capital", "nuestra comunidad", "los valencianos agradecemos", etc.

Més amunt ja havíem indicat que no hi ha cap carta escrita en català en què l'autor es presenti com a valencià, tampoc no en són gaires les que podem identificar en aquesta nova 
aproximació. Només hi ha un cas en què l'autora defensa la seva condició de valenciana per exigir la normalització de la llengua a l'església arran d'una visita al Museu de la catedral de València. Aquesta autora, però, ja s'havia presentat com a pertanyent a la Plataforma pel Dret a Decidir [4], per tant, l'exigència ("La nostra llengua ha de ser normalitzada en tots els àmbits de la vida") no sorprèn i s'adiu amb aquella autopresentació.

Un altre cas [14], és el del pintor Vicent Moreno Mira (columnista habitual a $\mathrm{La} \mathrm{Veu}$ del País Valencià i escriptor de cartes al director al Levante almenys des de 1988) ${ }^{9}$. L'autor fa una crítica aferrissada a una altra carta (a què ja hem fet referència [12]) que desaprova la intenció que la nova Televisió valenciana emeti només en valencià. En el seu discurs es refereix a la submissió dels valencians (entre els quals no s'inclou): “Tant m'ha impactat el contingut, que la incorporaré a un assaig que versa sobre l'obseqüència innocent dels valencians."

En una altra carta [13], el mateix autor fa una crítica de l'actuació del govern central envers els empresaris valencians i la ciutadania en general. En una al·legoria taurina justifica el tracte vexatori perquè no s'han jugat correctament "les cartes del valencianisme real -no el del Partit Popular, evidentment genuflex-". Al llarg del text, es poden resseguir una sèrie de tòpics que identifiquen clarament l'autor amb una posició reivindicativa dels empresaris i ciutadans: "¿No seria convenient exigir en lloc d'implorar, com farien els hòmens, el tracte que ens correspon?” o la més evident que recorre a l’expressió de l’himne valencià: “¿No s'han adonat que tanta ofrena anul·la la força i deslegitima la raó?" I acaba amb una certa crítica a l'espanyolisme identificada amb el món dels bous: "Ni sóc empresari ni ho he sigut mai. Però em fan llàstima quan els claven banderilles rojigualdas com si foren morlacos a punt de rebre l'última estocada ${ }^{10}$."

En un tercer exemple [16], l'autor elogia els articles de l'escriptor Carles Recio apareguts en el diari, els quals, segons ell, són molt interessants: “per descobrir tota (sic) València, les seues costums (sic), els seus barris, la seua gent, les seues anècdotes...”. Potser aquesta carta enllaça amb aquella tercera via de què hem parlat més amunt: un valencianisme (apartat del catalanisme) no gaire espanyolista. L'autor reconeix la tasca de Fuster en el llibre El País Valenciano, però creu que va ser "molt dolent amb el seu poble", en canvi Recio és "més didàctic". Finalment recomana als "actuals valencianistes de Compromís" que llegeixin els articles de Recio per adonar-se que la història del nostre país «a segut malfet (sic) i que queden molts forats negres», com per exemple les senyeres tricolors que es podien veure en l'exposició València Capital de la II República, cosa que li permet preguntar irònicament (als suposats interlocutors de Compromís) si ja existia el búnquer barraqueta el 1938.

Un últim exemple [17] incideix en el conformisme dels polítics i dels empresaris valencians davant del tracte desigual del govern central. La carta es refereix a la demanda del corredor mediterrani, però aprofita per criticar la proposta del PP valencià de tractar en les Corts la independència del valencià amb la finalitat de "amagar així la realitat de la discriminació econòmica i social que patim i sofrim per part del govern de l'estat espanyol ${ }^{11}$."

9 Universitat de València, 2002.

10 Volem destacar que l'autor empra, almenys en tres ocasions ('obseqüència', 'genuflex' i 'deslegitima'), lèxic que només apareix recollit en el DNV de l'AVL, no en el DIEC2 de l'IEC.

$11 \mathrm{http}: / / \mathrm{www}$. levante-emv.com/comunitat-valenciana/2017/02/08/pp-queda-defensa-valenciano-catalan/1526235.html 
En els quatre casos que hem aportat, i que es refereixen (recordem-ho) a les cartes escrites en valencià, trobem majoritàriament una identificació dels escriptors amb un territori valencià injustament tractat per les autoritats, cosa que justificaria una postura crítica amb el valencianisme conformista atribuït, generalment, a l'espanyolisme. Per una banda, tres autors culpen els governs valencians anteriors d'haver tingut una postura feble en les reivindicacions valencianes, cosa que podríem relacionar, precisament, amb la falta de consciència nacional valenciana en favor d'una nacionalitat espanyola, a la qual els valencians han contribuït amb les continuades majories absolutes aconseguides pel Partit Popular. D'una altra, la carta de la persona que es declara membre de la Plataforma pel dret a decidir, reclama el compromís de l'església valenciana amb la normalització de la llengua pròpia. Com és sabut, l'església valenciana va ser un factor clau en la castellanització del país des dels inicis del procés (Pitarch, 2001) i ha tingut un paper fonamental en el manteniment de l'espanyol com a llengua litúrgica fins als nostres dies ${ }^{12}$.

La darrera carta a què ens referirem, és la que reivindica l'obra de Carles Recio i la mostra com a vertadera recerca de la identitat valenciana, apartada, ja ho hem vist, de la que defensà Joan Fuster.

Considerem que cal per acabar aquest apartat fer referència a la correcció lingüística de les cartes publicades en valencià. Les cartes al director haurien de passar (com qualsevol text que apareix en un mitjà de comunicació escrit) per un filtre corrector, tant pel que fa a l'ortografia i a la gramàtica com a la coherència del contingut. Estem segurs que aquest procés (el de la correcció) es produeix en altres diaris que accepten la participació de lectors (i així ho hem demostrat en treballs anteriors) ${ }^{13}$ si atenem a les diverses versions d'una mateixa carta apareguda en dos (o tres) periòdics diferents. És ben sabut que la majoria de mitjans (escrits o audiovisuals) compten amb un llibre d'estil que adapta la normativa lingüística $\mathrm{i}$ altres característiques pragmaestilístiques que haurà de seguir qualsevol escriptor que hi col·labori (Vellón, 2013). Pel contrari, no som capaços de trobar aquesta acció correctora en el diari que ens ocupa; sembla que Levante dóna llibertat absoluta d'escriptura als col·laboradors i lectors quan ho fan en valencià, deixant que la correcció del text depengui solament dels coneixements i la intenció dels escriptors. Comprenem que el diari accepti textos que usin diverses opcions normatives (com per exemple les que ja havíem descrit abans en parlar dels mots emprats per Vicent Moreno Mira, nota 10) atenent a les variacions que proposa l'AVL del lèxic normatiu per al valencià respecte al diccionari de l'IEC; ara bé, no entenem la presència d'errors ortogràfics no permesos (que sapiguem) en cap de les propostes gramaticals a l'abast, com l'escriptura sense h del pretèrit a segut malfet que apareix en la carta [16] que acabem de comentar. Probablement, el diari pretén aglutinar tots els possibles lectors i impedir-ne l'autoexclusió per raons de model de llengua, cosa que no ocorre en cap dels mitjans que s'expressen en català (llevat, això sí, de les vel·leïtats literàries dels col·laboradors de renom que hi passegen els seus escrits). Val a dir, finalment, que no trobem cap errada d'aquestes característiques en les cartes escrites en espanyol, la qual cosa deu tenir una interpretació sociolingüística diàfana en què ara no ens detindrem.

12 Valgui com a mostra la negativa a introduir el català en la litúrgia, malgrat el manament del Concili Vaticà II (1964) i les demandes d'alguns clergues i molts ciutadans valencians (Riutort, 2002 i Pellisser, 2011).

13 Portalés, 2016. 


\subsubsection{Cartes en espanyol}

Moltes cartes escrites en castellà destil·len a través del discurs una identificació nacional espanyola, bé amb aquelles marques que abans havíem esmentat (díctics) bé amb el contingut mateix.

El primer exemple que aportem [18] és una nova crítica a l'alcalde de València, Joan Ribó, per totes aquelles actuacions que l'autor considera desencertades, desagradables o fins i tot insultants. Fonamentalment la imatge que es mostra de Ribó és la d'un catalanista i comunista i per a justificar-ho el remitent relata totes aquelles accions en què es mostren aquestes tendències. En primer lloc que vagi amb bicicleta per dalt de les voravies (?), en segon lloc, que pengi la bandera multicolor en el balcó de l'ajuntament el Dia de l'Orgull Gai i qualifiqui aquesta celebració de molt important. En tercer lloc, l'acusa que en la celebració de la Diada del 9 d'octubre, Ribó acudia de vesprada a una manifestació catalanista, en la qual: "ondeaba la bandera de Cataluña y a la par también las inconstitucionales esteladas y algunas banderas republicanas." Finalment, tampoc no li perdona la cavalcada de les Reines Magues en Nadal de 2016.

Encara que en cap moment s'esmenta la identificació de l'autor amb una ideologia espanyola, creiem que és prou eloqüent la defensa vehement dels valors tradicionals per contraposició als que sembla defensar l'alcalde. L'autor tampoc no s'identifica com a valencià, però sembla incloure's entre aquells que no comparteixen les imposicions i simpaties personals de Ribó:

Pues no está muy claro cuando siendo el alcalde, según él, de todos los valencianos, sí que impone en cuanto quiere lo que a él más le importa, sus imposiciones varias y sus simpatías ideológicas personales, aunque al resto de los demás valencianos, no le importa, que no les pueda agradar.

Un altre tema recurrent entre les cartes escrites en castellà és la conveniència de la reobertura de la Televisió Valenciana, arran de l'aprovació de la llei (12/2015 de 29 de desembre de 2015) que derogava la de tancament de l'emissió (Acord de 28 de novembre de 2013).

La primera carta que s'hi refereix [19] és la d'un lector que considera una despesa inútil la inversió en la televisió, mentre existeixin altres prioritats (segons ell, pàrquings i trams de metro). En dues ocasions, l'autor s'identifica com a valencià en usar l'expressió repetida "nuestra Comunidad" i reclama que es faci una consulta a la ciutadania perquè manifesti les seves preferències.

En el mateix sentit (fins i tot al·ludint a la carta anterior) es manifesta un altre lector [20] que repeteix, més o menys, els mateixos arguments. L'ús del possessiu reiteradament ("nuestra comunidad", "nuestra economia", "nuestros representantes") l'identifica amb la societat valenciana, tot i que s'hi refereix en tercera persona per tornar a la primera del plural en acabar l'argumentació: "los valencianos desearían que con su dinero se construyan escuelas, centros sanitarios, infraestructuras y otros gastos de mayor repercusión social, que mejoren nuestra economía y bienestar." L'ús de la tercera persona permet al locutor apartarse i donar un valor deòntic més general a l'afirmació.

Ja ens hem referit més amunt al cas d'alguns autors que criticaven l'ús exclusiu del valencià per a la nova televisió; mostrarem el cas ara d'una lectora [21] que es queixa de la mateixa exclusivitat en el cartell de Falles 2017. Enlloc no s'identifica com a valenciana, 
malgrat que, podem intuir que pertany al grup més majoritari quan afirma: "Me parece muy curioso, cuando en la ciudad de Valencia son pocos los que hablan valenciano, siendo la inmensa mayoría los que hablan castellano."

És habitual trobar-nos amb possessius que relacionen els autors amb l'Estat espanyol en criticar comportaments o actuacions que consideren nocius com en aquest exemple [22] en què s'incideix en la promoció del joc, de les apostes esportives que a través dels mitjans de comunicació envaeixen "nuestros hogares". L'autor valora l'increment que s'ha produït a Espanya i el relaciona amb la seva ("nuestro") llar.

En un altre cas [23], l'autor en queixar-se del preu de l'energia, remet a l'argumentació que Espanya és el país del sol, del clima privilegiat i d'altres recursos naturals que podrien servir per reduir el monopoli de les empreses elèctriques.

Novament [24], un lector fa referència a un informe de la UNESCO que analitza el fenomen “español de la generación ni-ni (ni estudian ni trabajan)" i no se n'està d'identificar-s'hi quan diu: "nos exhibe como el país con más fracaso escolar de Europa (un chaval de cada tres)."

Altres cartes es queixen del salari mínim espanyol, de l'augment de les pensions, de la manipulació de la premsa, de les dificultats de morir amb dignitat, del poc pes de l'estat en la presa de decisions internacionals, etc. En tots els casos, hi ha una clara identificació dels autors mitjançant les primeres persones verbals (en singular o plural), els pronoms personals o els possessius. Podríem pensar que els autors s'identifiquen amb la nacionalitat espanyola quan allò que denuncien pertany als afers de decisió estatals (salari mínim, pensions), la qual cosa obligaria a identificar-se amb una suposada valencianitat en queixar-se de la gestió autonòmica (educació, sanitat).

No seríem justos, però, si no atenguéssim a les cartes que manifesten una certa reivindicació valenciana o valencianista (encara que en siguin ben poques). La primera [25] reclama les obres (no sabem quines són) que no s'han construït al país i acaba amenaçant els governants estatals que la "Región Valenciana" esdevingui una "oveja negra" en aquesta "piel de toro". Sembla que, com ell diu, se sent desenganyat després d'haver donat suport a un partit amb fe i lleialtat perquè Espanya sortís de la crisi i ara se'n manifesti decebut.

Tres cartes més exalcen les particularitats valencianes des de diversos punts de vista. Un lector [26] que critica un article del professor Angel López sobre la proliferació de les curses populars a la ciutat de València, no se n'està de defensar-les i fins i tot d'afirmar: "Nos enorgullece el prestigio internacional de ser Valencia la Ciudad del Running". Un altre [27] critica les intencions del Partit Popular valencià de dividir els ciutadans (arran de la proposta de la sra. Bonig de debatre a les Corts si el valencià era una llengua diferent del català) per acabar amb una petició: "Sintámonos orgullosos de esta tierra a la que tenemos tantos motivos para amar y llevar en lo más hondo."

Acabem aquest repàs amb una carta [28] que exalça el que considera els símbols valencians fent ressò de la inauguració (el 17 de gener de 2017) de la nova seu de l'Associació Cultural Grup d'Acció Valencianista (GAV) al carrer Julián Peña de la ciutat. L'autora comença amb un entusiàstic "Valencia, iqué grande eres!" i fa un repàs per les icones de la ciutat (el Parterre, les torres, els miracles de Sant Vicent, la Cheperudeta, Almansa (?)) deixant per al final la lloança al GAV. Com és sabut, l'associació defensa la identitat valenciana, sobretot anticatalana. Tanmateix resulta sorprenent que l'autora inclogui entre les fites valencianes la ciutat d'Almansa, quan fou precisament allà (o a partir de la derrota que s'hi produí) que els valencians perderen les seves característiques diferenciadores. 
Hem deixat per al final una mostra de l'assumpció d'una cultura aliena que justifica la identificació nacional espanyola. Un lector [29], en analitzar els efectes de les malalties relacionades amb l'alimentació (anorèxia i bulímia), comença dient: "Nuestro escritor más internacional después de Cervantes, Vicente Blasco Ibáñez” per a fer entendre que l'abast d'aquelles malalties ben bé hi servirien perquè escrigués el cinquè genet de l'apocalipsi.

Una afirmació tan contundent ens remet clarament a les icones culturals de molts valencians, segons aquest autor no hi ha altre escriptor més internacional que Blasco Ibáñez que els identifiqui (com a espanyols) llevat del genial Cervantes. Ni un mot per a March o Martorell, Roís de Corella, Fuster o Estellés, deu ser perquè pensa que el fet d'escriure en valencià els treu internacionalitat.

\subsection{Altres màscares}

En la majoria dels casos que hem analitzat, ens hem trobat amb l'anomenat ethos col·lectiu, el desdoblament del locutor en primera persona del singular que sovint alterna amb la primera del plural. Hi ha cartes que alternen l'ús del jo i del nosaltres amb una intenció de desdoblament del locutor en locutor-enunciador. Calsamiglia (1993) considera que el canvi respon a la impossibilitat del locutor per manifestar-se com a expert en una determinada matèria i es presenta amb el col·lectiu que ja podria incloure'n les autoritats o els experts; ara bé, nosaltres considerem que, sovint, en aquestes situacions d'alternança de subjecte el jo es refereix a l'ethos experimental, el que ha vist o viscut els fets, mentre que nosaltres esdevé un subjecte valoratiu, de tal manera que la valoració està recolzada per tot de veus que la compartirien. En aquest sentit, preferim la interpretació de Calsamiglia i Tusón (2008: 129): "La identificación de la persona que habla con la primera persona del plural incorpora al locutor a un grupo. Es el grupo, entonces, el que proporciona al locutor la responsabilidad del enunciado".

L'ús de nosaltres busca sovint en les cartes al director (així com en els articles d'opinió o les columnes) la inclusió del lector en les valoracions, judicis, interpretacions de la realitat que fa una sola persona; es tracta, doncs, de la investidura d'una veu col·lectiva que en general ningú no ha atorgat al locutor, tot i que es fàcil que l'interlocutor s'hi reconegui si és que està inclòs.

La transmissió d'un ethos ideològic a través de les cartes al director és fàcil de detectar (com hem pogut comprovar en els exemples anteriors). La ideologia, tanmateix, no es manifesta únicament amb la identificació territorial; al llarg dels escrits regalimen tot de defenses de posicions relacionades amb la religió, el terrorisme, l'ensenyament, la identificació sexual, etc. I és aquí on l'autor s'ha de mullar, s'ha de despullar públicament i captar l'atenció dels seus conciutadans, per això, empra les persones gramaticals amb la intenció d'incloure col·lectius afins o per excloure'n els divergents i aconseguir així un major recolzament de la seva visió del món.

Entre les postures ideològiques més recurrents, trobem aquelles relacionades amb la religió. D'una banda, hi ha lectors [30] que manifesten les seves creences cristianes bé a través de reflexions fetes públiques: "Como acabamos de terminar un año, me gustaría proponer una meditación", bé defensant-se [31] d'allò que consideren una persecució: "Pero la Iglesia y los católicos no tenemos miedo porque Cristo nos dice todos los días: Yo estoy con vosotros, no temáis." 
Cal destacar que dues de les cartes estan escrites pel mateix autor (una en castellà i l'altra en català). De la primera hem extret l'exemple en el qual s'identifica com a catòlic i usa la primera persona del plural per diferenciar (precisament) els catòlics (nosaltres) d'aquells que suposadament els critiquen. En canvi, en la segona [32], el nosaltres inclou (en principi) a tota la humanitat que hauria d'actuar amb responsabilitat envers la natura i els éssers humans segons les indicacions del papa Francesc: "El papa Francesc ha insistit en Laudato que si les persones seguim comportant-nos amb la creació tal i com estem fent-ho fins ara, anem cap a l'autodestrucció."

Pel contrari, en una altra carta [33], que defensa la llibertat confessional i la laïcitat de l'estat, l'autor denuncia el toc de campanes que criden els catòlics als ritus religiosos $\mathrm{i}$ empra aquella primera persona del plural, precisament per excloure'ls: "No se puede ni se debe permitir que con argumentos tradicionales debamos seguir soportando las llamadas a los ritos religiosos de los católicos incumpliendo la ley."

Hem parat atenció com a exemple només en la identificació religiosa, però podríem allargar-nos i analitzar de manera detallada altres inclusions o exclusions socials (emigrants, ètnies diverses, grups dominants, col·lectius organitzats, etc.), perquè segons Van Dijk (2008: 210): “A causa de su relevancia en la estructura social y, por lo tanto, de su posición en la competición para acceder a los recursos sociales, algunos grupos representan el papel de grupos-referencia, como parte de su propia ideología."

\section{CONCLUSIÓ}

La majoria dels escriptors de cartes al director del diari Levante són homes, procedeixen de la ciutat de València i escriuen en castellà. En canvi, n'hi hem trobat ben pocs que s'identifiquin amb un ethos prediscursiu, només alguns es presenten com a testimonis autoritzats per tal de refutar informacions que consideren errònies o limitades (les professores, els ex-membres del comitè d'empresa o el metge) o sota un ethos determinat que augmentarà la percepció d'autenticitat d'allò que es relata (com en el cas del soci del València, el president del Gremi del Ventall, la dona de la Plataforma del Dret a Decidir o la nena de 2n d'ESO).

Hem vist com, en general, els escriptors de cartes al director del diari Levante que s'expressen en castellà identifiquen el fet de ser valencians no amb la llengua pròpia, ni amb senyes d'identitat que els puguin diferenciar de la resta de l'estat, sinó més aviat el contrari, amb una llengua forana $\mathrm{i}$ amb una exigència de permissivitat cap al nacionalisme espanyol que no reconeixen per al fet diferencial valencià.

Hem pogut constatar que les cartes escrites en castellà que inclouen en el text una identificació territorial valenciana defensen, en realitat, la pertinença a una societat espanyola monolingüe: l'exigència d'ensenyament en castellà o la denúncia d'uns mitjans de comunicació que s'expressarien únicament en valencià, així ho demostren. El mateix s'esdevé amb les cartes que no manifesten explícitament la identitat dels autors, malgrat que puguem reconèixer-la a través de les tries estilístiques que han emprat (amb díctics personals, possessius, referents toponímics o literaris); quan usen els possessius globals (nuestro, nuestros) es refereixen a realitats espanyoles (economia, joventut, etc.); l'ús del mot gobierno s'identifica exclusivament amb el govern central de Madrid, o quan se citen referents literaris es redueixen als escriptors en castellà, per exemple. 
Només les cartes escrites en català (i unes poques escrites en castellà) reclamen millors condicions de finançament, millors infraestructures o l'orgull de sentir-se valencians.

Podem concloure doncs, que l'ús de possessius inclusius o persones gramaticals col·lectives es refereixen, en general, en les cartes escrites en castellà a la societat que defensa una idea unitària de la nació que la faria coincidir amb l'estat i per contra, els mateixos díctics usats en les cartes en català reduirien el referent al col·lectiu valencià que reclama (amb major o menor vehemència) millors condicions de vida per als ciutadans de la seva comunitat.

Pel que fa a la transmissió ideològica no territorial (i posant com a exemple exclusivament la religiosa) hem pogut comprovar que la primera persona del plural sol identificar els col·lectius als quals pertany el locutor i confrontar-los amb els altres (en tercera del plural) que generalment són considerats agressors ("la Iglesia y los católicos no tenemos miedo") o denunciats per una conducta irregular ("soportando las llamadas a los ritos religiosos de los católicos incumpliendo la ley").

\section{Referències bibliogràfiques}

Amossy, R. (ed.) (1999). Images de soi dans le discours - La construction de l'ethos. Lausanne: Delachaux et Niestlé.

Amossy, R. (2010). La présentation de soi. Ethos et identité verbale. Paris: PUF.

Amossy, R. i Herschberg, A. (1997). Stéréotypes et clichés. Paris: Nathan. [Hi ha una versió en espanyol (2001): Estereotipos y clichés. Buenos Aires: Eudeba]

Calsamiglia, H. (1993). «Singularidades de la elaboración textual». En Lomas, C. i Osoro, A. El enfoque comunicativo en la enseñanza de la lengua. Barcelona: Paidós, pp. 181-198.

Calsamiglia, H. i Tusón, A. (2008). Las cosas del decir. Barcelona: Ariel.

Castelló, R. (2000). «Algunes hipótesis sobre els nacionalismes valencians», Diàlegs, pp. 57-90.

Conill, J.J. (2016). «Llengua, cultura, normalització», L'Espill, 53: 61-81.

Ducrot, O. (1972). Le dire et le dit. París: Editions de Minuit. [Hi ha una traducció a l'espanyol (1986): El decir y lo dicho. Barcelona: Paidós.]

Flor, V. (2010). «La instrumentació mediàtica de la identitat valenciana». Arxius, 23, pp. 113-122.

Fraser, N. (1990). «Rethinking the Public Sphere: A Contribution to the Critique of Actually Existing Democracy», Social Texts, 25/26, pp. 56-80.

Goffman, E. (1981). La presentación de la persona en la vida cotidiana. Buenos Aires: Amorrortu.

Gómez Espino, J. M. i Blanco López, J. (2005): «Los niños en la publicidad. Una propuesta de categorización de las representaciones sociales sobre la infancia en los anuncios televisivos.», ZER, 19, pp. 53-76.

Gomis, Ll. (1991). «Les cartes al director com a barem de la receptivitat periodística», Periodística, 4, pp. 89-93.

Gomis, Ll. (2008). Teoría de los géneros periodísticos. Barcelona: UOCpress.

Habermas, J. (1989). Justification and application: Remarks on discourse ethics (Translated by Ciaran P. Cronin). Cambridge, Massachusetts: The MIT Press.

Maingueneau, D. (1999). «Ethos, scénographie, incorporation». En Amossy, R. (ed.). Images de soi dans le discours. La construction de l'èthos. Lausanne: Delachaux et Niestlé, pp. 75-100.

Maingueneau, D. (2010). «El enunciador encarnado». Versión, 24: 203-225. http://148.206.107.15/ biblioteca_digital/articulos/7-502-7189ibk.pdf [20-5-2016]

Maingueneau, D. (2014). «Le recours à l'ethos dans l'analyse du discours littéraire». Fabula / Les colloques, Posture d'auteurs: du Moyen Âge à la modernité. http://www.fabula.org/colloques/ document2424.php [1-6-2017] 
Nielsen, R. K. (2010). «Participation through Letters to the Editor: Circulation, Considerations, and Genres in the Letters Institution». Journalism 11/1, pp. 21-35.

Pelermann, Ch. i Olbrechts-Tyteca, L. (1989). Tratado de la argumentación. Madrid: Gredos.

Pellisser, N. (2011). El solc de l'escriptura. El discurs mediàtic de Martí Domínguez i Barberà.València: Universitat de València.

Pitarch, V. (2001). Llengua i església durant el Barroc valencià. València, Barcelona: IIFV i PAM.

Portalés, E. (2016). Les cartes al director, una eina d'aprenentatge. En Camps, A.; Casas, M.; Camajoan, Ll. i Puntí, T. (Coords.). L'ensenyament del català als territoris de parla catalana. Vic: Universitat de Vic, pp. 277-287.

Portalés, E. (2017). Argumentació i educació discursiva: el gènere cartes al director en l'ensenyament. Benicarló: Onada.

Pradilla, M. A. (2008). La tribu valenciana. Benicarló: Onada.

Riutort, P. (2002). «Francesc Ferrer Pastor: l'home del compromís constant». En Universitat de València: Francesc Ferrer Pastor: les paraules d'un poble. València: Universitat de València, pp. 77-90.

Rojas Lizana, I. (2009). Letters to the editor in the local press: genre and discourse in everyday texts from Australia and Chile. Saarbucken: VDM Verlag Dr Muller.

Universitat de València (2002). Francesc Ferrer Pastor: les paraules d'un poble. València: Universitat de València.

Van Dijk, T. (1993). Elite discourse and racism. Newbury Park, Califòrnia: SAGE.

Van Dijk, T. (2008). «Semántica del discurso e ideología». Discurso \& Sociedad, 2/1, pp. 201-261.

Van Dijk, T. (2009). Discurso y poder. Barcelona: Gedisa.

Vellón, J. (2013). Norma y estilo en los libros de redacción. Salamanca: Comunicación Social.

Wahl-jorgensen, K. (2007). Journalist and the public: Newsroomculture, letters to the editor, and democracy. Creskill, NJ: Hampton Press.

Xambó, R. (2010). «Els mitjans de comunicació al País Valencià». Arxius, 23, pp. 3-16.

Young, N. (2013). «Working the Fringes: The Role of Letters to the editor in Advancing Non-Standard Media Narratives About Climate Changes». Public Understanding of Science, 22/4, pp. 443-459. 